\title{
Analisis Matthew Correlation Coefficient pada K-Nearest Neighbor dalam Klasifikasi Ikan Hias
}

\author{
Novia Hasdyna ${ }^{1}$, Rozzi Kesuma dinata ${ }^{2}$ \\ ${ }^{1}$ Program Studi Teknik Informatika, Universitas Islam Kebangsaan Indonesia \\ 2,Program Studi Teknik Informatika, Universitas Malikussaleh \\ ${ }^{1}$ noviahasdyna@gmail.com, ${ }^{2}$ rozzi@,unimal.ac.id
}

\begin{abstract}
K-Nearest Neighbor (K-NN) is a machine learning algorithm that functions to classify data. This study aims to measure the performance of K-NN algorithm by using Matthew Correlation Coefficient (MCC). The data that used in this study are the ornamental fish which consisting of 3 classes named Premium, Medium, and Low. The analysis results of the Matthew Correlation Coefficient on K-NN using Euclidean Distance obtained the highest MCC value in Medium class which is 0.786542 . The second highest MCC value is in Premium class which is 0.567434 . The lowest MCC value is in Low class which is 0.435269 .

Overall, the MCC values is statistically which is 0,596415 .
\end{abstract}

Keyword: Matthew correlation coefficient, machine learning, knn, ikan hias

\section{Introduction}

Saat ini perkembangan ruang lingkup analisis data science yang sedang berkembang pesat adalah machine leraning [1]. Machine learning atau pembelajaran mesin merupakan bagian dari artificial intelligence yang terdiri dari supervised learning, unsupervised learning, dan reinforcement learning [2]. Algoritma supervised learning antara lain adalah support vector machine, naïve bayes, $k$-nearest neighbor, dan random forest [3]. Supervised learning berfungsi untuk mengklasifikasikan data berdasarkan pola yang sudah ada [4].

Banyak metode yang dipakai untuk mengukur kinerja algoritma machine learning [5]. Pada penelitian ini, untuk mengukur kinerja algoritma K-Neirest Neighbor digunakan matthew correlation coefficient. Matthew correlation coefficient mengukur performansi klasifikasi data dengan range $-1,0,+1$ [6]. Semakin nilai MCC mendekati +1 maka semakin baik kinerja algoritma klasifikasinya. Sebaliknya, jika nilai nya mendekati -1, maka semakin buruk kinerja algoritma klasifikasi. Pengukuran terhadap kinerja suatu sistem klasifikasi merupakan hal yang penting [7]. Kinerja sistem klasifikasi menggambarkan seberapa baik sistem dalam mengklasifikasikan data.

Penelitian ini menggunakan algoritma k-nn untuk mengklasifikasikan data ikan hias. Adapun klasifikasi ikan hias terdiri dari 3 class, yaitu premium, medium dan low. Hasil yang diharapkan pada penelitian ini berupa nilai performance Matthew Correlation Coefficient (MCC) pada algoritma knn dalam mengklasifikasikan data ikan hias. Pada proses klasifikasi ikan hias ini akan memberikan informasi hasil pengujian data ikan hias termasuk kedalam grade premium, medium atau grade low berdasarkan konversi nilai pada atribut perawatan, warna, pakan, dan harga.

\section{Research Method}

\subsection{Framework Penelitian}

Adapun framework penelitian ini adalah seperti pada gambar 1 .

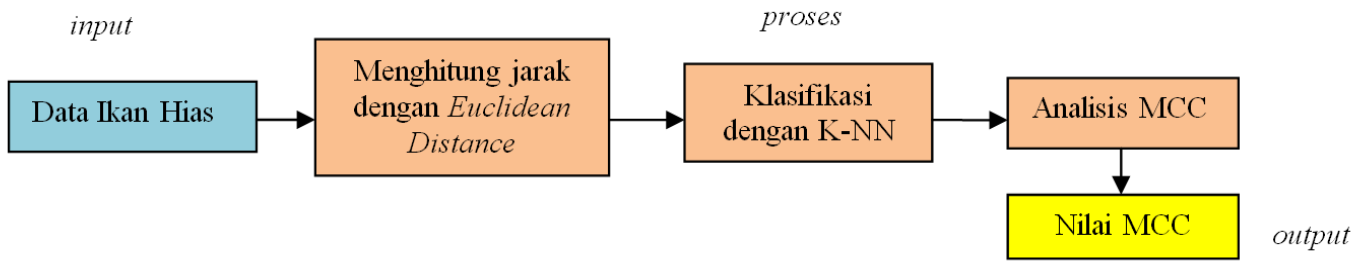

Gambar 1. Framework Penelitan 
Berdasarkan gambar 1, skema penelitian ini terdiri dari tiga proses yaitu input, proses dan output. Setelah melakukan inputan data ikan hias, selanjutnya akan dilakukan proses perhitungan jarak dengan menggunakan Euclidean distance. Jarak terkecil akan dilakukan proses pengklasifikasian dengan $k$-nearest neighbor. Hasil klasifikasi berdasarkan data training dan data testing akan dianalisis performance nya dengan menggunakan matthew correlation coefficient. Semakin nilai mcc mendekati +1 maka semakin baik kinerja algoritma klasifikasinya. Sebaliknya, jika nilai nya mendekati -1, maka semakin buruk kinerja algoritma klasifikasi.

\subsection{K-Nearest Neighbor}

Salah satu metode klasifikasi terhadap sekumpulan data berdasarkan pembelajaran data yang sudah terklasifikasikan sebelumya adalah K-NN [8]. K-NN termasuk dalam golongan supervised learning, dimana hasil query instance yang baru diklasifikasikan berdasarkan mayoritas kedekatan jarak dari kategori yang ada dalam K-NN [9]. Berikut ilustrasi K-NN seperti pada gambar 2.

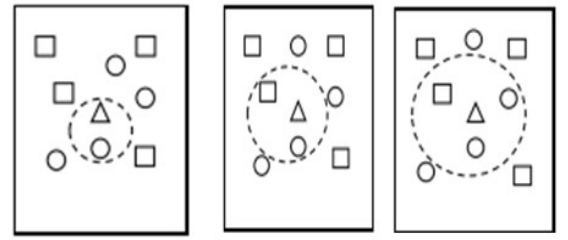

Gambar 2. Ilustrasi K-NN dengan $\mathrm{k}=1$, $\mathrm{k}=2$, dan $\mathrm{k}=3$

K- Nearest Neighbor bekerja mencari jarak yang paling dekat antara data yang akan di evaluasi dengan $\mathrm{k}$ neighbor ( tetangga ) yang terdekat di dalam sebuah data traning [10].

Berikut urutan proses kerja algoritma K- Nearest Neighbor [11]:

1. Tentukan Parameter k jumlah tetangga paling dekat.

2. Hitung Euclidean Distance masing masing objek terhadap sampel data yang ada.

$$
d_{i}=\sqrt{\sum_{i=1}^{p}\left(x_{2 i}-x_{1 i}\right)^{2}}
$$

Keterangan:

$$
\begin{aligned}
& \mathrm{x} 1=\text { Sampel data } \\
& \mathrm{x} 2=\text { Data uji atau data testing } \\
& \mathrm{i}=\text { Variabel data } \\
& \mathrm{d}=\text { Jarak } \\
& \mathrm{p}=\text { Dimensi data }
\end{aligned}
$$

3. Kemudian mengurutkan objek-objek tersebut kedalam kelompok yang mempunyai jarak Euclid kecil.

4. Mengumpulkan kategori Y (Klasifikasi Nearest Neighbor).

\subsection{Matthew Correlation Coefficient}

Matthew Correlation Coefficient (MCC) merupakan salah satu metode yang digunakan untuk mengukur kinerja algoritma klasifikasi. Perhitungan awal mcc dilakukan dengan menggunakan confusion matrix. Pada dasarnya confusion matrix mengandung informasi yang membandingkan hasil klasifikasi yang dilakukan oleh sistem dengan hasil klasifikasi yang seharusnya.

Koefisien Korelasi Matthews (MCC) memiliki rentang -1 hingga 1 di mana -1 menunjukkan klasifikasi biner yang sepenuhnya salah sedangkan 1 menunjukkan klasifikasi biner yang sebenarnya. Berikut adalah formula dari MCC:

$$
M C C=\frac{T P x T N-F P \times F N}{\sqrt{(T P+F P)(T P+F N)(T N+F P)(T N+F N)}}
$$


Keterangan:

$\begin{array}{ll}\mathrm{FN} & =\text { False Negative } \\ \mathrm{TP} & =\text { True Possitive } \\ \mathrm{TN} & =\text { True Negative } \\ \mathrm{FP} & =\text { False Possitive } \\ \mathrm{MCC} & =\text { Matthew Correlation Coefficient }\end{array}$

\section{Result and Analysis}

\subsection{Data Training}

Adapun dataset ikan hias dapat dilihat pada tabel 1 .

Tabel 1. Data Training

\begin{tabular}{cccccc}
\hline $\begin{array}{c}\text { Nama } \\
\text { Ikan }\end{array}$ & Perawatan & Warna & Pakan & Harga & Grade \\
\hline Fish A & 5 & Sangat Menarik & Binatang Kecil & Puluhan Juta & Premium \\
Fish B & 5 & Sangat Menarik & Binatang Kecil dan Pelet & Puluhan Juta & Premium \\
\hline Fish C & 5 & Sangat Menarik & Pelet dan Tumbuhan & Jutaan & Premium \\
\hline Fish D & 4 & Sangat Menarik & Pelet dan Tumbuhan & Jutaan & Premium \\
\hline Fish E & 5 & Sangat Menarik & Pelet & Ratusan Ribu & Premium \\
Fish F & 4 & Menarik & Binatang Kecil dan Pelet & Puluhan Ribu & Medium \\
Fish G & 3 & Sangat Menarik & Pelet dan Tumbuhan & Puluhan Ribu & Medium \\
\hline Fish H & 3 & Sangat Menarik & Pelet & Puluhan Ribu & Medium \\
Fish I & 3 & Menarik & Pelet & Puluhan Ribu & Medium \\
\hline Fish J & 3 & Menarik & Tumbuhan & Puluhan Ribu & Medium \\
Fish K & 2 & Menarik & Pelet & Ribuan & Low \\
Fish L & 2 & Netral & Pelet & Ribuan & Low \\
Fish M & 2 & Kurang Menarik & Pelet & Ribuan & Low \\
\hline Fish N & 2 & Sangat Kurang Menarik & Pelet & Ribuan & Low \\
Fish O & 1 & Kurang Menarik & Tumbuhan & Ribuan & Low \\
\hline
\end{tabular}

Pada tabel 1, menampilkan data training yang terdiri dari 15 data, dengan kriteria perawatan, warna, pakan, harga, dan grade ikan hias terdiri dari tiga class yaitu premium, medium dan low. Untuk data atribut dan nilainya dapat dilihat pada tabel 2 .

Tabel 2. Atribut dan Nilainya

\begin{tabular}{cll}
\hline No & Nama & Jenis atribut dan Nilainya \\
\hline $\mathbf{1}$ & Ikan Hias & Kategori (Nama Ikan) \\
$\mathbf{2}$ & Kemudahan Perawatan & Numerik \\
$\mathbf{3}$ & Warna & $\begin{array}{l}\text { Kategori (Sangat Menarik, Menarik, Netral, } \\
\text { Kurang Menarik, Sangat Kurang Menarik) }\end{array}$ \\
$\mathbf{4}$ & Pakan & $\begin{array}{l}\text { Kategori (Binatang Kecil dan pelet, Pelet dan } \\
\text { Tumbuhan, Binatang Kecil, Tumbuhan, Pelet) }\end{array}$ \\
$\mathbf{5}$ & Harga & $\begin{array}{l}\text { Kategori (Puluhan Juta, Jutaan, Ratusan ribu, } \\
\text { Puluhan ribu, Ribuan) }\end{array}$ \\
\hline
\end{tabular}

\subsection{Data Testing}

Data testing pada proses klasifikasi ikan hias dengan KNN ditampilkan pada tabel 3.

Tabel 3. Data Testing

\begin{tabular}{lccccc}
\hline $\begin{array}{l}\text { Nama } \\
\text { Ikan }\end{array}$ & Perawatan & Warna & Pakan & Harga & Grade \\
\hline Blue Tang & 5 & 4 & 2 & 3 & $?$ \\
Pare Tawar & 4 & 2 & 5 & 3 & $?$ \\
Clown Fish & 4 & 4 & 2 & 2 & $?$ \\
Gurame & 3 & 4 & 1 & 1 & $?$ \\
\hline
\end{tabular}

Pada tabel 3, menampilkan data testing yang terdiri dari 4 data, yaitu ikan blue tang, pare tawar, clown fish, dan gurame. Data testing tersebut akan dilakukan proses klasifikasi dengan KNN. Selanjutnya pada tabel 4 menampilkan data konversi warna. 
Tabel 4. Konversi Warna

\begin{tabular}{cc}
\hline Kriteria Warna & Nilai \\
\hline Sangat Menarik & 5 \\
Menarik & 4 \\
Netral & 3 \\
Kurang Menarik & 2 \\
Sangat Kurang Menarik & 1 \\
\hline
\end{tabular}

Data konversi warna seperti pada tabel 4 diatas terdiri dari 5 kriteria warna, yaitu sangat menarik, menarik, netral, kurang menarik dan sangat kurang menarik. Adapan data konversi pakan dapat dilihat pada tabel 5.

\begin{tabular}{cc}
\multicolumn{2}{|c}{ Tabel 5. Konversi Pakan } \\
\hline Kriteria Pakan & Nilai \\
\hline Binatang Kecil & 5 \\
\hline Binatang Kecil dan Pelet & 4 \\
Pelet dan Tumbuhan & 3 \\
Pelet & 2 \\
Tumbuhan & 1 \\
\hline
\end{tabular}

Untuk data konversi harga dengan kriteria puluhan juta, jutaan, ratusan ribu, puluhan ribu, dan ribuan ditampilkan pada tabel 6 .

\begin{tabular}{cc}
\multicolumn{2}{c}{ Tabel 6. Konversi Harga } \\
\hline $\begin{array}{c}\text { Kriteria } \\
\text { Harga }\end{array}$ & Nilai \\
\hline Puluhan Juta & 5 \\
Jutaan & 4 \\
Ratusan Ribu & 3 \\
Puluhan Ribu & 2 \\
Ribuan & 1 \\
\hline
\end{tabular}

Adapun konversi data training dapat dilihat pada tabel 7.

Tabel 7. Konversi Data Training

\begin{tabular}{cccccc}
\hline $\begin{array}{c}\text { Nama } \\
\text { Ikan }\end{array}$ & Perawatan & Warna & Pakan & Harga & Grade \\
\hline Fish A & 5 & 5 & 5 & 5 & Premium \\
\hline Fish B & 5 & 5 & 4 & 5 & Premium \\
\hline Fish C & 5 & 5 & 3 & 4 & Premium \\
\hline Fish D & 4 & 5 & 3 & 4 & Premium \\
\hline Fish E & 5 & 5 & 2 & 3 & Premium \\
\hline Fish F & 4 & 4 & 4 & 2 & Medium \\
\hline Fish G & 3 & 5 & 3 & 2 & Medium \\
\hline Fish H & 3 & 5 & 2 & 2 & Medium \\
\hline Fish I & 3 & 4 & 2 & 2 & Medium \\
\hline Fish J & 3 & 4 & 1 & 2 & Medium \\
\hline Fish K & 2 & 4 & 2 & 1 & Low \\
\hline Fish L & 2 & 3 & 2 & 1 & Low \\
\hline Fish M & 2 & 2 & 2 & 1 & Low \\
\hline Fish N & 2 & 1 & 2 & 1 & low \\
\hline Fish O & 1 & 1 & 1 & 1 & Low \\
\hline
\end{tabular}

\subsection{Hasil Klasifikasi K-NN}

\subsubsection{Menghitung parameter $k$}

Untuk menghitung parameter $\mathrm{k}$ jumlah tetangga paling dekat akan ditentukan secara manual. Pada penelitian ini mengambil nilai $\mathrm{k}=3$. 


\subsubsection{Hasil Perhitungan Jarak dengan Euclidean Distance}

Untuk menghitung jarak tetangga terdekat dengan Euclidean Distance pada data testing pertama dapat dilakukan dengan cara seperti berikut:

$$
\begin{aligned}
\mathrm{d}(\text { Blue Tang }), \mathrm{d}(\text { fish } \mathrm{A}) & =\sqrt{(5-5)^{2}+(4-5)^{2}+(2-5)^{2}+(3-5)^{2}} \\
& =3,74 \\
\mathrm{~d}(\text { Blue Tang), } \mathrm{d}(\text { fish B }) & =\sqrt{(5-5)^{2}+(4-5)^{2}+(2-4)^{2}+(3-5)^{2}} \\
& =3,00 \\
\mathrm{~d}(\text { Blue Tang), } \mathrm{d}(\text { fish C) } & =\sqrt{(5-5)^{2}+(4-5)^{2}+(2-3)^{2}+(3-4)^{2}} \\
& =1,73 \\
\mathrm{~d}(\text { Blue Tang), } \mathrm{d}(\text { fish } \mathrm{D}) & =\sqrt{(5-4)^{2}+(4-5)^{2}+(2-3)^{2}+(3-4)^{2}} \\
& =2,00 \\
\mathrm{~d}(\text { Blue Tang), } \mathrm{d}(\text { fish E) } & =\sqrt{(5-5)^{2}+(4-5)^{2}+(2-2)^{2}+(3-3)^{2}} \\
& =1,00
\end{aligned}
$$

Adapun hasil perhitungan jarak pada data testing ke-1 dengan menggunakan Euclidean distance berdasarkan data testing terhadap data training dapat dilihat pada tabel 8 .

Tabel 8. Hasil Perhitungan Jarak Data Test 1 (Blue Tang)

\begin{tabular}{lcll}
\hline $\begin{array}{l}\text { Nama } \\
\text { Ikan }\end{array}$ & Jarak & Grade & k=3 \\
\hline Fish A & 3,74 & Premium & \\
Fish B & 3,00 & Premium & \\
Fish C & 1,73 & Premium & K2 \\
Fish D & 2,00 & Premium & K3 \\
Fish E & 1,00 & Premium & K1 \\
Fish F & 2,45 & Medium & \\
Fish G & 2,65 & Medium & \\
Fish H & 2,45 & Medium & \\
Fish I & 2,24 & Medium & \\
Fish J & 2,45 & Medium & \\
Fish K & 3,61 & Low & \\
Fish L & 3,74 & Low & \\
Fish M & 4,12 & Low & \\
Fish N & 4,69 & Low & \\
Fish O & 5,48 & Low & \\
\hline
\end{tabular}

Berdasarkan tabel 8, diperoleh hasil jarak terkecil senilai 1,00 sehingga ikan Blue Tang termasuk ke dalam klasifikasi ikan grade premium. Adapun hasil perhitungan jarak pada data testing kedua ditampilkan pada tabel 9 .

Tabel 9. Hasil Perhitungan Jarak Data Test 2 (Pare Tawar)

\begin{tabular}{lclc}
\hline $\begin{array}{l}\text { Nama } \\
\text { Ikan }\end{array}$ & Jarak & Grade & k=3 \\
\hline Fish A & 3,74 & Premium & K3 \\
Fish B & 3,87 & Premium & \\
\hline Fish C & 3,87 & Premium & \\
Fish D & 3,74 & Premium & K2 \\
Fish E & 4,36 & Premium & \\
Fish F & 2,45 & Medium & K1 \\
Fish G & 3,87 & Medium & \\
Fish H & 4,47 & Medium & \\
\hline Fish I & 3,87 & Medium & \\
Fish J & 4,69 & Medium & \\
\hline
\end{tabular}




\begin{tabular}{lll}
\hline Fish K & 4,58 & Low \\
Fish L & 4,24 & Low \\
Fish M & 4,12 & Low \\
Fish N & 4,24 & low \\
Fish O & 5,48 & Low \\
\hline
\end{tabular}

Berdasarkan tabel 9, diperoleh hasil jarak terkecil senilai 2,45 sehingga ikan Pare Tawar termasuk ke dalam klasifikasi ikan grade medium. Adapun hasil perhitungan jarak pada data testing ketiga ditampilkan pada tabel 10

\begin{tabular}{|c|c|c|c|}
\hline $\begin{array}{l}\text { Nama } \\
\text { Ikan }\end{array}$ & Jarak & Grade & $\mathbf{k}=\mathbf{3}$ \\
\hline Fish A & 4,47 & Premium & \\
\hline Fish B & 3,87 & Premium & \\
\hline Fish C & 2,65 & Premium & \\
\hline Fish D & 2,45 & Premium & \\
\hline Fish E & 1,73 & Premium & \\
\hline Fish F & 2,00 & Medium & \\
\hline Fish G & 1,73 & Medium & \\
\hline Fish $\mathrm{H}$ & 1,41 & Medium & K3 \\
\hline Fish I & 1,00 & Medium & K1 \\
\hline Fish J & 1,41 & Medium & $\mathrm{K} 2$ \\
\hline Fish K & 2,24 & Low & \\
\hline Fish L & 2,45 & Low & \\
\hline Fish M & 3,00 & Low & \\
\hline Fish N & 3,74 & low & \\
\hline Fish O & 4,47 & Low & \\
\hline
\end{tabular}

Tabel 10 menampilkan hasil perhitungan jarak terkecil senilai 1,00 sehingga ikan Clown Fish termasuk ke dalam klasifikasi ikan grade medium. Adapun hasil perhitungan jarak pada data testing ketiga ditampilkan pada tabel 11 .

\begin{tabular}{|c|c|c|c|}
\hline $\begin{array}{l}\text { Nama } \\
\text { Ikan }\end{array}$ & Jarak & Grade & $\mathbf{k}=\mathbf{3}$ \\
\hline Fish A & 6,08 & Premium & \\
\hline Fish B & 5,48 & Premium & \\
\hline Fish C & 4,24 & Premium & \\
\hline Fish D & 3,87 & Premium & \\
\hline Fish E & 3,16 & Premium & \\
\hline Fish F & 3,32 & Medium & \\
\hline Fish $\mathrm{G}$ & 2,45 & Medium & \\
\hline Fish $\mathrm{H}$ & 1,73 & Medium & \\
\hline Fish I & 1,41 & Medium & K3 \\
\hline Fish J & 1,00 & Medium & K1 \\
\hline Fish K & 1,41 & Low & $\mathrm{K} 2$ \\
\hline Fish L & 1,73 & Low & \\
\hline Fish M & 2,45 & Low & \\
\hline Fish N & 3,32 & low & \\
\hline Fish O & 3,61 & Low & \\
\hline
\end{tabular}

Berdasarkan tabel 10, diperoleh hasil jarak terkecil senilai 1,00 sehingga ikan Gurame termasuk ke dalam klasifikasi ikan grade medium.

\subsection{Hasil Analisis Matthew Correlation Coefficient}

Untuk menganalisis MCC, proses yang pertama adalah dengan menghitung confusion matrix. Nilai dari confusion matrix ditampilkan pada tabel 12 . 
Tabel 12. Proses I Confusion Matrix

\begin{tabular}{|c|c|c|c|c|}
\hline \multirow{4}{*}{$\begin{array}{l}\text { predicted } \\
\text { class }\end{array}$} & & premium & medium & low \\
\hline & premium & 3 & 0 & 0 \\
\hline & medium & 0 & 4 & 1 \\
\hline & low & 0 & 0 & 4 \\
\hline
\end{tabular}

Proses kedua confusion matrix dapat dilihat pada tabel 13.

Tabel 13. Proses II Confusion Matrix

\begin{tabular}{lccccc}
\hline \multirow{2}{*}{$\begin{array}{l}\text { predicted } \\
\text { class }\end{array}$} & TP & FP & FN & TN \\
\cline { 2 - 6 } & premium & 3 & 0 & 0 & 2 \\
& medium & 4 & 0 & 0 & 1 \\
\hline
\end{tabular}

Setelah proses confusion matrix, maka akan dihitung nilai MCC dengan menggunakan persamaan 2. Adapun hasil perhitungan MCC ditampilkan pada tabel 14.

Tabel 14. Nilai Matthew Correlation Coefficient

\begin{tabular}{lcl}
\hline No & Class & MCC \\
\hline 1 & Premium & 0,567434 \\
2 & Medium & 0,786542 \\
3 & Low & 0,435269 \\
& Rata-rata MCC & 0,596415 \\
\hline
\end{tabular}

Berdasarkan tabel 14, dapat dilihat bahwa nilai MCC pada class medium senilai 0,786542 merupakan nilai MCC terbaik. sSedangkan nilai MCC terendah adalah pada class low dengan nilai 0,435269. Semakin mendekati angka +1 maka semakin bagus kinerja algoritma klasifikasi, sedangkan semakin mendekati -1 maka semakin buruk kinerja algoritma klasifikasi.

Adapun nilai MCC dalam bentuk grafik dapat dilihat pada gambar 3.

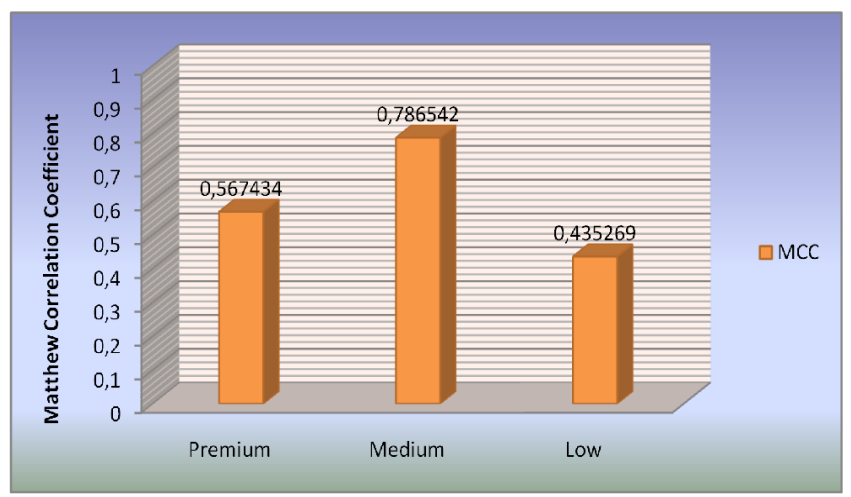

Gambar 3. Grafik hasil analisis Matthew Correlation Coefficient pada Klasifikasi Ikan Hias dengan KNN

\section{Conclusion}

Penelitian ini menganalisis kinerja algoritma klasifikasi KNN dalam pengklasifikasian data ikan hias. Hasil penelitian ini menunjukkan bahwa nilai matthew correlation coefficient pada k-nn dengan menggunakan Euclidean distance diperoleh nilai MCC tertinggi pada class medium sebesar 0,786542. Nilai mcc tertinggi kedua pada class premium senilai 0,567434. Nilai mcc terendah adalah pada class low sebesar 0,435269. Dengan demikian, dapat dikatakan nilai korelasi matthew yang paling baik adalah pada class medium karena class medium adalah yang paling mendekati +1 . Sebaliknya nilai MCC pada class low adalah yang paling mendekati 0. Adapun rata-rata nilai MCC pada klasifikasi data ikan hias dengan KNN adalah senilai 0,596415. Oleh karena itu, kinerja algoritma klasifikasi KNN adalah baik.

Adapun saran dari penulis adalah agar pembaca dapat melakukan analisis kinerja algoritma klasifikasi dengan metode yang lain, seperti metode $k$-fold cross validation. 


\section{References}

[1] M. E. Saputra, H. Mawengkang, and E. B. Nababan. "Gini Index With Local Mean Based For Determining K Value In K-Nearest Neighbor Classification." Journal of Physics: Conference Series. Vol. 1235. No. 1. IOP Publishing, 2019.

[2] R. K. Dinata, F. Fajriana, K. Khairunnisa,"Penerapan Algoritma Classification And Regression Trees (Cart) Pada Penerimaan Anggota Baru Unit Kegiatan Mahasiswa (UKM) Di Universitas Malikussaleh Berbasis WEB". TECHSI-Jurnal Teknik Informatika, 10(2), 74-81, 2018

[3] W. Wahyono, I. N. P. Trisna, S. L. Sariwening, M.Fajar, D. \& Wijayanto, "Perbandingan penghitungan jarak pada k-nearest neighbour dalam klasifikasi data tekstual". Jurnal Teknologi dan Sistem Komputer, $8(1), 54-58,2020$.

[4] W. Wardhani, A. Khrisna, "Implementasi Algoritma K-Means untuk Pengelompokkan Penyakit Pasien pada Puskesmas Kajen Pekalongan,” J. Transform., vol. 14, no. 1, pp. 30-37, 2016.

[5] L.Farokhah, "Implementasi K-Nearest Neighbor untuk Klasifikasi Bunga Dengan Ekstraksi Fitur Warna RGB". Jurnal Teknologi Informasi dan Ilmu Komputer, 7(6), 2020

[6] R. P. Saputri, W. S. Winahju, K. Fithriasari, "Klasifikasi Sentimen Wisatawan Candi Borobudur pada Situs TripAdvisor Menggunakan Support Vector Machine dan K-Nearest Neighbor". Jurnal Sains dan Seni ITS, 8(2), 349-356, 2020

[7] S. A. Naufal, A. Adiwijaya, W. Astuti "Analisis Perbandingan Klasifikasi Support Vector Machine (SVM) dan K-Nearest Neighbors (KNN) untuk Deteksi Kanker dengan Data Microarray". JURIKOM (Jurnal Riset Komputer), 7(1), 162-168, 2020.

[8] R. K. Dinata, F. Fajriana, \& N. Hasdyna, "Klasifikasi Sekolah Menengah Pertama/Sederajat Wilayah Bireuen Menggunakan Algoritma K-Nearest Neighbors Berbasis Web". Computer Engineering, Science and System Journal, 5(1), 33-37, 2020.

[9] I. Hasimah, M. A. Mukid, H. Yasin, "Klasifikasi Calon Debitur Kredit Pemilikan Rumah (Kpr) Multiguna Take Over Menggunakan Metode K Nearest Neighbor Dengan Pembobotan Global Gini Diversity Index". Jurnal Gaussian, 8(4), 407-417, 2020

[10] Y. I. Kurniawan, T. I. Barokah, "Klasifikasi Penentuan Pengajuan Kartu Kredit Menggunakan K-Nearest Neighbor". Jurnal Ilmiah Matrik, 22(1), 73-82, 2020

[11] M. A. P. Arsyad. "Klasifikasi Penyakit Breast Cancer Menggunakan Naïve Bayes Dan KNN". PhD Thesis. Universitas Muhammadiyah Malang, 2020 